\title{
Trends in alcohol consumption in undergraduate third level students: 1992-1999
}

\author{
S O'Brien. H Sinclair, S Soni, T O'Dowd', D Thomas \\ Student Health Service and Department of Community Health and General Practice , Trinity College, Dublin, \\ Ireland
}

\begin{abstract}
Background Alcohol consumption has increased in the Irish population in recent years. It is not known to what extent the student population has been affected by this increase.

Aim To determine levels of alcohol consumption among undergraduates in one Irish university and identify changes in drinking patterns in the years 1992-1999.

Methods Information on alcohol use was obtained by anonymous self-completed questionnaire in a stratified random cross-faculty sample of undergraduates in 1992 and 1999. The CAGE questionnaire to determine problem drinking was included in both surveys.

Results A statistically significant ( $p=0.01$ ) drop in weekly alcohol consumption by males was found, although the proportion of male problem drinkers increased. Consumption for females remained the same.

Conclusions Findings are contrary to recent figures for drinking patterns in young Irish people in general. The fall in alcohol consumption in male students may be linked to improved male insight into the negative effects of alcohol or to the substitution of cheaper available substances.
\end{abstract}

\section{Introduction}

Alcohol consumption has increased in the Irish population in recent years.' This has been linked with economic growth, greater access to alcohol through longer opening hours, a greater number of young people starting to drink at a younger age and a higher percentage of regular drinkers by the age of 18 years. It has also been linked with strong alcohol advertising and sponsorship of highly visible sports.

Alcohol consumption is an integral part of student life. It is socially acceptable and is seen as characteristic of students to indulge in frequent and often heavy drinking/ It is not known to what extent the Irish student population has been affected by the general increase in drinking levels. A survey of undergraduate student alcohol use and attitudes towards alcohol in one large Irish university had been carried out in 1992/ It was felt timely to repeat this survey using the same methodology in 1999 in order to ascertain the changes, if any, that have taken place in the intervening time.

\section{Methods}

Information on alcohol use and attitudes towards alcohol was obtained by. $\mathrm{m}$ anonymous, pretested, 60 item, self-administered questionnaire covering basic demographic data, frequency and quantity of alcohol use, effects of alcohol use iacademic, medical, financial and social), motives for drinking and attitudes towards alcohol. The CAGE questionnaire, a four item questionnaire used to detect problem drinking was also included in both surveys. ${ }^{4}$ Two or more positive replies on the CAGE are said to identity problem drinkers. Sensible drinking was defined as an intake of $<21$ units per week for a man and <14 units per week for a woman/ Binge drinking was defined as drinking over half the sensible number of units per week in one session."

In both surveys, all students in randomly selected classes (>50 students), stratified by year and faculty were included in the study. Since all students were to be surveyed in each selected class, it was necessary to restrict classes in the sampling frame to those with less than 50 students to ensure adequate representation across all years and faculties. A sample size of 407 students was considered necessary to ensure adequate year and faculty representation in 1992. A slightly larger sample of 503 students was considered necessary to ensure similar representation in 1999.

Questionnaires were administered at the beginning or end of scheduled lectures following explanation of their anonymous and voluntary nature. Almost all students attending the selected lectures completed the questionnaires. The number of non-attenders at these lectures is not known. To ensure compatibility between both surveys, the original 1992 questionnaires were recoded in accordance with the 1999 coding protocol.

The study was approved by the College Student Health Committee and permission from heads of faculties and class lecturers was sought and given in all cases.

\section{Statistical analysis}

Differences between groups were tested using the two-tailed Student's t-test, the Pearson Chi-squared test or Fisher's exact test where appropriate.

\section{Results}

Response rates were high in both surveys, 400 (response rate 98.3\%) questionnaires were returned completed in 1992 compared with 501 (response rate 99.6\%) in 1999. There was no difference in the male to female ratio or the average age of students in both surveys (see Table 1). While a slightly larger proportion of students reported drinking alcohol in 1999 (92\%) compared to $1992(89.5 \%)$, this was not statistically significant $(\mathrm{p}>0.05)$. All results are based on those who drank alcohol in both survey periods. The average number of units of alcohol drunk per week by male students dropped from 22 in 1992 to 17 in 1999, a drop that was statistically significant $(p=0.01$, see 
Table 2). There was little change in the average weekly consumption by female students between 1992 and 1999 .

The number of male students drinking above the sensible limit guidelines (21 units per week) dropped significantly between the two study periods $(\mathrm{p}=0.01)$. The number of females drinking above the limit guidelines (14 units per week increased but not significantly (p-0.59). The proportion of males engaged in binge drinking dropped from $40 \%$ in 1992 to $29 \%$ in 1999, a drop that was statistically significant (p-0.04 . Female binge drinking remained approximately the same. The proportion of students with two or more positive replies on the CAGE questionnaire increased between the two survey periods but the increase was much larger for male students rising from 29\% in 1992 to 39\% in 1999 (see Table 2).

More students in 1999 thought that student alcohol consumption was largc" (see Table 3). Students in 1999 were also more likely to set a higher safe upper limit of drinking per week for both a healthy man and woman and were also more likely to exceed their perceived safe upper limits more than once a week. Most students in both surveys felt that they were a 'normal" drinker. The term 'normal being self-determined.

A higher percentage of students in 1999 reported receiving a physical injury while drinking or having had a complete loss of memory because of drinking (see Table 4). Students in 1999 were also much more likely to engage in indiscriminate sexual activity while drinking. While a larger proportion of students in 1999 felt that they ought to cut down on their drinking, very few were interested in attending talks on drinking and health.

More students in 1999 claimed they had missed practicals or lectures because of drinking but that this was not interfering with their academic performance (see Table 5). While there was little difference in the numbers experiencing financial difficulties due to drinking, a larger proportion of students in 1999 felt they were spending too much money on drink.

\section{Discussion}

These findings are the first indications of trends in drinking patterns and attitudes to alcohol in an Irish third level student population. The study is likely to underestimate problem drinkers who may miss lectures due to the after-effects of alcohol. Those students with more severe alcohol problems are also likely to be off the college register or indeed left the university. Where male students are concerned there has been a reduction in the amount of alcohol consumed weekly, in the numbers of students exceeding sensible limit guidelines and in the number of binge drinkers.

These findings are surprising and it is difficult to be certain as to the reason for the fall in male alcohol consumption. It is possible that it may be linked to improved male insight into the negative effects of alcohol through school-based health education programmes, although it would be reasonable to expect a similar pattern in female drinking if they are exposed to alcohol programmes. Such programmes have been shown to prompt more sensible drinking habits, less frequent drinking and less drunkenness."

A number of studies have reported that male college students drink alcohol more frequently than female students, "drink larger quantities of alcohol *'' and are more likely to engage in binge drinking. "A recent British study " of 3,075 second-year university students from ten UK universities has shown that $61 \%$ of the men and $48 \%$ of the women drinkers exceeded "sensible" limits of 21 units per week for men and 14 units for women. These percentages are higher than in the study reported here. In another study which also showed that male students drank significantly larger quantities than female, men were also
Table 1. Comparison between 1992 and 1999 students (drinkers and non-drinkers) for baseline characteristics. Values are numbers (percentages) unless otherwise stated.

\begin{tabular}{|c|c|c|c|}
\hline Chairacteristtc & $\begin{array}{c}1992 \\
(n=400)\end{array}$ & $\begin{array}{l}1999 \\
(n=501)\end{array}$ & $P$ value \\
\hline \multicolumn{4}{|l|}{ Gender } \\
\hline Men & $164(41.1)$ & $203(40.6)$ & \\
\hline Women & 235 (58.9) & $297(59.4)$ & $0.88^{\star}$ \\
\hline $\begin{array}{l}\text { Mean age in years } \\
\text { (SD) } \\
\text { Drink alcohol }\end{array}$ & $20.0(1.7)$ & $20.2(3.2)$ & $0.14 t$ \\
\hline Yes & 358 (89.5) & $461(92.0)$ & \\
\hline No & $42(10.5)$ & $40(8.0)$ & $0.19^{*}$ \\
\hline
\end{tabular}

Table 2. Gender differences in alcohol consumption between 1992 and 1999. Values are numbers (percentages) unless oth erwise stated.

\begin{tabular}{|c|c|c|c|}
\hline Alcohol consumption & 1992 & 1999 & $P$ value* \\
\hline \multicolumn{4}{|c|}{ Average number of units drunk weekly: } \\
\hline Males (SD) & $21.9(18.6)$ & $17.1(14.9)$ & 0.012 \\
\hline Females (SD) & $10.5(10.2)$ & $10.5(8.9)$ & 0.962 \\
\hline \multicolumn{4}{|c|}{ Above weekly limit guidelines } \\
\hline Males & $52(38.5)$ & $40(24.5)$ & 0.009 \\
\hline Females & $54(27.1)$ & $62(24.7)$ & 0.558 \\
\hline \multicolumn{4}{|c|}{ One or more 'binge' days during last week: } \\
\hline Males & $54(40.0)$ & $47(28.8)$ & 0.043 \\
\hline Females & $65(32.7)$ & $77(30.7)$ & 0.653 \\
\hline \multicolumn{4}{|c|}{ CAGE (two or more positives) } \\
\hline Males & $42(29.2)$ & $72(38.7)$ & 0.071 \\
\hline 'Females & $52(25.4)$ & $73(27.1)$ & 0.665 \\
\hline
\end{tabular}

Table 3. Comparison of student knowledge and practices regarding alcohol limit guidelines between 1992 and 1999. Values are numbers (percentages) who said 'Yes'.

$\begin{array}{llll}\text { Knowledge of } & 1992 & 1999 & P \text { value* } \\ \text { limit guidelines } & & & \end{array}$

Student alcohol consumption

$\begin{array}{llll}\text { Large } & 246(69.1) & 366(79.6) & \\ \text { Moderate } & 108(30.3) & 91(19.8) & \\ \text { Small } & 2(0.6) & 3(0.7) & 0.001\end{array}$

Safe upper limit for a healthy man

Below limit guidelines 119(33.3) 122(26.6)

Above limit guidelines $238(66.8) \quad 337(73.4) \quad 0.036$

Safe upper limit for a healthy woman

Below limit guidelines $255(71.4) \quad 279(61.1)$

$\begin{array}{llll}\text { Above limit guidelines } \quad 102(28.6) & 178(38.9) & 0.002\end{array}$

Do you exceed the limits you suggested above?

More than once a week $76(21.3) \quad 140$ (31.1)

Less than once a week 234 (65.5) $269(59.8)$

$\begin{array}{llll}\text { Never } & 47(13.2) & 41(9.1) & 0.004\end{array}$

Compared to other students, do you believe that you drink

$\begin{array}{lll}\text { Less } & 188(42.0) & 216(47.1)\end{array}$

As much $\quad 140(39.4) \quad 211(56.0)$

More 27(7.6) 32(7.0)

0.17

Do you feel you are a normal drinker?

* Pearson Chi-squared test 
Table 4. Effects of alcohol on student health between 1992 and 1999. Values are numbers (percentages) who said 'Yes'.

\begin{tabular}{|c|c|c|c|}
\hline Health effects & 1992 & 1999 & $P$ value \\
\hline \multicolumn{4}{|c|}{ Have you received any physical injuries while drinking? } \\
\hline & $96(27.2)$ & $211(45.9)$ & $<0.001 *$ \\
\hline \multirow{2}{*}{\multicolumn{4}{|c|}{$\begin{array}{l}\text { Have you had a complete loss of memory because of drink } \\
\qquad 126(36.0) 206(45.0) 0.01^{*}\end{array}$}} \\
\hline & & & \\
\hline \multirow{2}{*}{\multicolumn{4}{|c|}{$\begin{array}{l}\text { Have you had DTs (delirium tremens), i.e. severe shaking, } \\
\text { heard voices or seen things that were not there, as a result } \\
\text { heavy drinking? }\end{array}$}} \\
\hline & & & \\
\hline & $34(9.7)$ & $42(9.2)$ & $0.81^{*}$ \\
\hline \multicolumn{4}{|c|}{ Do you crave a drink at a definite time daily? } \\
\hline & $16(4.6)$ & $16(3.5)$ & $0.44^{*}$ \\
\hline \multicolumn{4}{|c|}{$\begin{array}{l}\text { Have you had a drink first thing in the morning to steady yc } \\
\text { nerves or get rid of a hangover? }\end{array}$} \\
\hline & $9(2.6)$ & $49(10.7)$ & $0.001 \mathrm{~T}$ \\
\hline \multicolumn{4}{|c|}{ Have you been involved in indiscriminate sexual activity wh } \\
\hline drinking? & $89(25.3)$ & $147(32.2)$ & $0.033^{*}$ \\
\hline \multicolumn{4}{|c|}{ Have you felt you ought to cut down on your drinking? } \\
\hline & $110(31.3)$ & $185(40.3)$ & $0.008^{*}$ \\
\hline \multicolumn{4}{|c|}{$\begin{array}{l}\text { Would you be interested in attending talks on drinking and } \\
\text { health"? }\end{array}$} \\
\hline & $93(26.5)$ & $72(16.7)$ & $0.001^{*}$ \\
\hline
\end{tabular}

Table 5. Effects of alcohol on academic life and performance between 1992 and 1999. Values are numbers (percentages) who said 'Yes'.

Academic life and performance $19921999 \quad$ Pvalue $^{*}$

Have you missed practicals or lectures because of drinking? $168(47.5) 280(61.0)<0.001^{*}$

Has drinking interfered with your preparation for exams? 43(12.2) 66(14.4) $0.35^{*}$

Is drinking affecting your academic performance?

$$
\text { 55(15.6) 78(17.1) } 0.58^{*}
$$

Is alcohol making your college life unhappy?

$$
17(4.8) \quad 1(0.2) \quad<0.001 \mathrm{t}
$$

Has your drinking pattern changed since you started college? $201(57.4) 333(72.2)<0.001 *$

Do you drink alone?

$$
47(13.4) \quad 44(9.6) \quad 0.09^{*}
$$

Have you had financial difficulties as a result of drinking? 75(21.2) 96(20.8) $0.90^{*}$

Have you felt you spend too much money on your drinking? $168(47.7) 287(62.4)<0.001^{*}$

* Pearson Chi-squared test, t Fisher's exact test.

more likely than the women to have a current alcohol-use disorder."

A study of binge drinking in American students between 1993 and 1997 has shown a slight decrease in percentage or binge drinkers between the two study periods as in this study. ${ }^{14}$ Student binge drinkers have been shown to be"'"' times more likely than 'non-binge' drinkers to engage in unplanned and unprotected sexual activity, increasing the likelihood of unwanted pregnancies and contracting STDs, including AIDS.'*

This study is the only one to use recent comparative data on all the parameters reported above and it raises the question that the male decline in drinking may be linked to the availability of other cheaper substances/drugs which may be used as substitutes tor alcohol by male students. Significant correlations between alcohol drinking, tobacco smoking and illicit drug use have recently been reported in a student population."' Ours is the only srudy to use recent comparative data on all the parameters reported above and it raises the question that the male decline in drinking may be linked to the availability of other cheaper substances/drugs which may be used as substitutes for alcohol by male students. If this is true, it suggests that male students may be experimenting with other substances more than their female counterparts.

This is the basis for further research being conducted by the research group into current substance misuse by university students using qualitative methodologies.

\section{Acknowledgements}

This research work was funded by the Provost's Research Fund, Trinity College, Dublin. We would like to thank Dr Myra O'Regan, senior lecturer. Department of Statistics, for her assistance in compiling the original study questionnaire and Mary Smith for her expertise with data entry. The authors would also like to acknowledge the generous assistance of the lecturing staff of the College, staff members of the Student Health Service and the participating students for facilitating the study.

\section{References}

1. Harkin AM, Anderson P, Lehto J. Alcohol in Europe: A Health Perspective. WHO Regional Office for Europe. Copenhagen, 1995.

2. Royal College of Physicians. Alcohol and the young. / $R$ Coll Phys London 1995;29: 470-4.

3. O'Brien S, O'Regan M. Patterns of student drinking. Proc Royal Coll Psych Ann Meet 1992; 93.

4. Mayfield D, McLeod G, Hall P. The CAGE Questionnaire: validation of a new alcoholism screening instrument. $A m$ ] Psychiatry 1974; 131(10): 1121-3.

5. Edwards G. Sensible drinking. Br Med J 1996; 312: 1.

6. Moore L, Smith C, Catford J. Binge drinking: prevalence, patterns and policy. Health Educ Res 1994; 9: 497-505.

7. Werner M, Walker L, Greene J. Screening for problem drinking among college freshmen. JAdolesc Health 1994; 15: 303-10.

8. CDC. Youth risk behaviour surveillance: National College Health Risk Behaviour Survey - United States 1995, MMWR. 1997; 46: 1-56.

9. Roche A, Watt K. Drinking and university students: From celebration to inebriation: Drug Alcohol Rev 1999; 18 (4): 389-99.

10. Engs RC, Diebold BA, Hanson DJ. The drinking patterns and problems of a national sample of college students. I Alcohol Drujf Educ 1996; 41; 13-33.

11. Johnston LD, O'Malley PM, Bachman JG. National Survey Results on Drug Use from the Monitoring the Future Study, 1975-1995, Vol II, College Students and Young Adults. Rockville, MD: US Dept of Health and Human Services, National Institute on Drug Abuse, NIH Publication Nos 98-4140; 1997. 
12. Webb E, Ashton C, Kelly P, Kamali F. Alcohol and drug use in UK university students. Lancet 1996; 348: 922-25.

13. Clements R. Prevalence of alcohol-use disorders and alcoThoi related problems in a college sutdent sample. College Health 1999; 48: 111-118.

14. Wcchsler H, Dowdall G, maenncr G, Gledhill-Hoyt J, Lee $\mathrm{H}$. Changes in binge drinking and related problems among American college students between 1993 and 1997. College Health 1998; 47: 57-68.

15. Wechhsler H, Isaac N. "Binge" drinkers at Massachusetts colleges. JAMA, 1992; 267: 21: 2929-2931.

16. Yang MS, Yang MJ, Liu YH, Ko YC. Prevalence and related rik factors of licit and illicit substances use by adolescent students in Southern Taiwan. Public Health 1998; 112: 347-352.

Correspondence to: Prof. Tow O'Dowd, Department of Community Health <r General Practice, Trinity College Centre for Health Sciences, Adelaide \&"Meath Hospital, incorporating the National Children V Hospital, Tallaght, Dublin 24, Ireland. Tel: +353 1 6081087/6082293; Fax: +3531 4031211/4031212 